\title{
A ZOPACAS e a Defesa no Brasil, Argentina e Uruguai
}

\author{
ZOPACAS and Defense in Brazil, Argentina and Uruguay \\ Cláudio de Carvalho Silveira ${ }^{1}$
}

\section{Resumo}

Este texto tem por objetivo geral abordar aspectos da percepção sobre a criação da Zona de Paz e Cooperação do Atlântico Sul (ZOPACAS) no âmbito dos países sulamericanos, ao completar três décadas de sua existência, com o foco nos temas de segurança internacional e defesa, existentes nessa região. De maneira mais específica, abordaremos algumas dessas percepções sobre a ZOPACAS ocorridas na República Federativa do Brasil, República Argentina e República Oriental do Uruguai. Neste período, os três países se tornaram, membros da ZOPACAS, e parceiros na União das Nações Sul-Americanas (UNASUL) e no Mercado Comum do Sul (MERCOSUL). Além destas instituições, a ZOPACAS, colaborou na cooperação internacional na área de defesa, que promoveram o aumento de iniciativas e possibilidades de manter a paz, a confiança mútua e a estabilidade na região.

Palavras-chave: Zona de Paz e Cooperação, Atlântico Sul, Forças Armadas, Brasil, Argentina, Uruguai

\section{Abstract}

This text has as general objective to approach aspects of the perception about the creation of the South Atlantic Peace and Cooperation Zone (ZOPACAS) in the scope of the South American countries, when completing three decades of its existence, with the focus on the themes of international security and defense, existing in that region. In a more specific way, we will address some of these perceptions about ZOPACAS that occurred in the Federative Republic of Brazil, Argentina and the Eastern Republic of Uruguay. During this period, the three countries became members of ZOPACAS and partners in the Union of South American Nations (UNASUR) and in the Southern Common Market (MERCOSUR).In addition to these institutions, ZOPACAS collaborated in international cooperation in the area of defense, which promoted an increase in

Recibido: 27 de septiembre de 2020 Aceptado: 20 de abril de 2020 Publicado: 10 de julio de 2020

${ }^{1}$ Graduado em Filosofia (UERJ). Graduado em Ciências Sociais (UERJ).Mestre em Ciências Sociais (UFRJ). Doutor em Ciências Sociais (UNICAMP). Professor do Departamento e do Programa de Pós-Graduação de Relações Internacionais do Instituto de Filosofia e Ciências Humanas da UERJ. Correo electrónico: ccsilv@yahoo.com 
initiatives and possibilities to maintain peace, mutual trust and stability in the region.

Keywords: Zone of Peace and Cooperation, South Atlantic, Armed Forces, Brazil, Argentina, Uruguay

\section{Introdução}

A importância da ZOPACAS para os três países aqui mencionados, em elação à defesa, tem a ver com a manutenção de uma ordem estável e resolução pacífica de controvérsias no âmbito dos demais países do Atlântico Sul, onde se pode considerar também outras entidades globais, regionais, e sub-regionais que trabalhem para os mesmos objetivos. Isto, a fim de que as atividades relacionadas possam ser realizadas, juntamente com aquelas concernentes à preservação da soberania dos países, proteção das rotas do comércio internacional, exploração controlada dos recursos naturais, segurança da navegação marítima e aérea, assistência humanitária, manutenção da paz, construção de confiança mútua. Além disso, promover outras várias ações de intercâmbio e cooperação na área de defesa com o uso de recursos humanos e materiais, que envolvem saberes e produtos das esferas civis e militares. Assim, a entidade possui seu valor, pois, representa um reconhecimento de que seus países membros exerçam diversas formas de concerto internacional pacífico em sua área. Ademais, que a mesma seja livre de conflitos bélicos mundiais, convencionais ou não, e das interferências de potências extraregionais, sobretudo, as que tenham pretensão de exercício de dominação de alcance global.

A partir daí, nosso objetivo específico aqui é o de abordar as concepções sobre vantagens e problemas existentes na criação e desenvolvimento da Zona de Paz e Cooperação do Atlântico Sul (ZOPACAS) a partir daquilo que é expresso, nas questões de defesa do Brasil, Argentina e Uruguai, considerando a participação de alguns atores, tais como, governos meios de comunicação, analistas acadêmicos e membros das Forças Armadas dessas nações. O período aqui analisado é desde a criação das ZOPACAS até seus trinta anos, quase simultaneamente situados com o fim os governos progressistas nestes países.

Ressaltamos que, em nenhum momento, desconsideramos os demais participantes do entorno estratégico, como os países africanos membros da ZOPACAS, pois também procuram desenvolver satisfatoriamente esta organização de arranjo regional. Isto pode ser verificado através, por exemplo, da iniciativa de Angola que possui fortes ligações históricas com o Brasil e os demais países africanos ocidentais. Outro caso é o interesse da África do Sul, manter intercâmbio intenso com os países 
mercosulinos, com a criação do Fórum IBAS (Índia, Brasil e África do Sul) o dos BRICS (Índia, Brasil, Rússia, Índia, China e África do Sul).

Seria igualmente desaconselhável descartar a presença dos interesses da Namíbia e seus acordos com a Marinha do Brasil (MB) para treinamento e modernização de as força naval ou expectativa da assinatura de um acordo semelhante entre o Brasil e o Senegal.

Também, não desprezamos as iniciativas bilaterais entre Argentina e África do Sul no âmbito diplomático e econômico ao longo do tempo. Consideramos que esta situação demonstra que houve interesses sul-americanos em trabalhar conjuntamente na prevenção de tradicionais ameaças (guerras e conflitos bélicos) e novas ameaças (narcotráfico, crime organizado, desastres ambientais, tráfico ilegal de armas, pirataria, migrações ilegais etc). Tal prevenção age na resolução pacífica de controvérsias, combate ao combate ao crime organizado, à pirataria, e demais delitos internacionais, além da ajuda humanitária a calamidades, apoio de infraestrutura de serviços públicos e privados de todas as áreas, inclusive a defesa, como também pensado para o Conselho de Defesa Sul-Americano (CDS) da UNASUL (Ministério das Relações Exteriores, 2016).

Em função destes aspectos da política internacional, abordamos a visão da tríade Brasil, Argentina e Uruguai sobre as possibilidades e a efetivação de cooperar entre si e com os africanos, na área de defesa e segurança internacional, a fim de ajudar na realização de expectativas existentes sobre a ZOPACAS, ao longo de sua história.

Assim, uma questão importante é a existência da iniciativa de cooperação na realidade de países ditos subdesenvolvidos ou emergentes (como é o caso dos sulamericanos e africanos) membros da ZOPACAS. Apesar de manterem condições desfavoráveis de infraestrutura e bem-esta social, houve uma determinação política de vencer estas dificuldades e alcançar relativo êxito no âmbito da concertação SulSul.

Nosso propósito em tratar do Brasil, Argentina e Uruguai tem a ver com o fato de serem as nações sul-americanas, membros da ZOPACAS, ao mesmo tempo, países com importância econômica e política no MERCOSUL. Além disso, se tornaram constituintes e parceiros da UNASUL, em suas diversas tarefas, onde as questões de segurança internacional e defesa estão presentes. Estes três países possuem algumas características próprias e outras comuns, que podem ser complementares. Junto com Paraguai, constituíram as intensões e realizações fundamentais de criação do MERCOSUL, pelo Tratado de Assunção, de 1991, ao qual se agregaram outras nações sul-americanas, a seu modo, desde então. Além do mais, Brasil, Argentina e Uruguai possuem também um respeito internacional por sua tradição diplomática e respeito à ordem internacional e a busca pela paz, seja no subcontinente, na 
América Latina ou no plano global. Eles primaram pela manutenção e aperfeiçoamento de realizações no intercâmbio e cooperação do mesmo, procurando incrementá-lo, visando manter, entre si, os valores e ações da tradição diplomática que conquistaram historicamente. Por fim, apesar de o Brasil ser considerado, dentre esses três países, o que possui maior aparato militar e a maior base industrial de defesa, eles buscaram valorizar e juntar certas capacidades específicas neste setor, para produzir bens e serviços mútuos.

$\mathrm{O}$ trabalho está dividido em três partes e uma consideração final. Na primeira tratamos da origem e o desenvolvimento da ZOPACAS pela Organização das Nações Unidas (ONU). Na segunda, dos temas e problemas daquela organização. Na terceira, enfocamos alguns debates acerca do seu funcionamento. Além destas, descrevemos nossas considerações finais.

\section{Origem e Importância da ZOPACAS}

Foi o governo de José Sarney (1985-1990) que apresentou a proposta de criação da ZOPACAS ainda no contexto da Guerra Fria e do intento dos países da região de afastar as possibilidades de conflitos oriundos no âmbito interno e externo ao espaço sul-atlântico. Naquele momento já havia as preocupações sobre a lógica geopolítica de projeção da influência brasileira no seu entorno estratégico, com a adaptação de teorias europeias para analisar a realidade do nosso subcontinente e corroborar a marcha para o oeste brasileiro para integrá-lo plenamente, ao território nacional.

Aliado a isso, houve o exercício da elaboração das justificativas para ampliar a atuação do Brasil no lado do Pacífico, como é o caso da concepção dos trabalhos de militares como Mário Travassos (1947), Meira Mattos (1958), e Golbery Silva (1967). Sem desconsiderarem a vertente continental do Leste, o Atlântico Sul teve, assim, seu valor reconhecido para a interligação econômica, política e cultural entre os países sul-americanos e africanos (Costa, 1991:196).

A decisão da Organização das Nações Unidas (ONU) de criar a ZOPACAS em 1986 por iniciativa brasileira foi acolhida pela comunidade internacional e teve o apoio de vários países, a abstenção de dezessete membros e a negativa dos Estados Unidos da América (EUA). Vale lembrar ainda que, nesta época a sigla dessa entidade, em português, então ZPACAS, foi substituída posteriormente, por ZOPACAS, para harmonizar com aos idiomas espanhol e francês, sem ferir seu significado em português.

A ZOPACAS é composta por um total de 24 países, a saber: África do Sul, Angola, Argentina, Benin, Brasil, Cabo Verde, Camarões, Congo, Costa do Marfim, Gabão, Gâmbia, Gana, Guiné-Conacri, Guiné-Bissau, Guiné-Equatorial, Libéria, Namíbia, 
Nigéria, República Democrática do Congo, São Tomé e Príncipe, Senegal, Serra Leoa, Togo e Uruguai (Ministério da Defesa, 2013).

A despeito da postura estadunidense, o acolhimento da proposta de criação dessa veio ao encontro dos interesses dos países em preservar uma parte do globo livre de intervenções conflitos militares e armamentos nucleares. Isto foi feito, dando continuidade a um processo histórico recente de pacificação, que foi interrompido na região com a Guerra das Malvinas entre Argentina e Reino Unido, em 1982.

O contexto de criação da ZOPACAS envolveu também a manutenção do Tratado de Tlatelolco de 1967 e da vigência do Tratado de Pelindaba de 1996, sobre a desnuclearização da área e a discussão sobre a propriedade dos países aderirem ou não ao Tratado de Não Proliferação Nuclear (TNP) e seus protocolos adicionais, o que revelaram uma problemática advinda das dificuldades de relacionamento entre os países do Norte e do Sul. Estas iniciativas ocorreram depois da discussão sobre o "congelamento do poder mundial" pelas superpotências, como nas declarações da diplomacia brasileira desde os anos da Política Externa Independente (PEI) e durante o governo ditatorial militar brasileiro (Fonseca Jr, 2006:448).

Mesmo com o exposto acima o Atlântico Sul continuou sendo uma região com grande presença militar de potências internas e externas à região, como os EUA e o Reino Unido. Ela se deu através de suas bases nas ilhas dispostas em seu interior até a região subantártica, onde se localizam as Malvinas.

Desta maneira, os africanos mantiveram relações históricas com os sul-americanos mesmo aqueles, a exemplo dos lusófonos, sem a mesma herança cultural comum, mas com interesses políticos e econômicos às vezes mais, às vezes menos próximos, como Argentina e África do Sul (Lechini, 2004:243-265). Esta posição representa que o pensamento dos países da bacia sul-atlântica estava voltado para a manutenção da paz e da soberania aérea e marítima e terrestre de seus estados sem pretensões de projeção de poder militar para conquista e ofensa aos seus vizinhos ou a países de fora do seu entorno estratégico.

Neste contexto, é importante ressaltar que a criação da União das Repúblicas SulAmericanas (UNASUL) e a incorporação do Conselho de Defesa Sul-Americano (CDS) por esta entidade, ajudaram os esforços de Brasil, Argentina e Uruguai em tentar possibilitar o desenvolvimento da ZOPACAS. O CDS aspira um ambiente regional que prima pela integração e cooperação militar a partir de operações e exercícios conjuntos, formação profissional, interoperabilidade, pesquisa de ciência e tecnologia, base industrial de defesa etc. que seja benéfica para a referida tríade e ser estendido aos demais países membros das ZOPACAS.

A própria UNASUL foi um esforço político singular de tentar atribuir relevância a um contexto geográfico e seu grau de articulação. Até então, apenas o determinismo 
geográfico fazia com que doze nações dividissem o mesmo espaço do continente americano. Até sua criação, havia uma preocupação maior com o termo América Latina, envolvendo também o México e os países da América Central, por causa de certa conformação econômico-social e histórico-cultural de suas carências e níveis de subdesenvolvimento (Carmo 2013:141). Contudo, a fim de buscar certo grau de autonomia frente à hegemonia da Europa e dos EUA, os sul-americanos se movimentaram para criar um condomínio próprio sem deixar de se entenderem latino-americanos. Porém, conservaram interesses e problemas mais específicos, capazes de dotarem a sub-região da capacidade de construir alguma unidade que lhe dê certa identidade e relativa homogeneização.

Aqui podemos inserir a situação mercosulina, que também ajudou a dar impulsos nas expectativas da UNASUL, mesmo considerando diversos problemas e dificuldades nos seus tratados constitutivos, respectivamente assinados em Assunção e em Brasília. Percebe-se assim que as questões relacionadas à defesa fazem parte do escopo dessa organização, dadas as características e objetivos do CDS, que podem ser exploradas a fim de contribuir para a melhoria do estatuto da ZOPACAS evidenciado nas questões apresentadas neste texto. Estas são duas entidades distintas em seus objetivos, mas podem ser complementares em relação à postura de manutenção da paz e resolução de conflitos nessa parte do mundo.

A partir da conferência das Nações Unidas em Estocolmo, em 1972, questões ambientais e econômicas se tornaram relevantes no contexto internacional. Estas foram igualmente importantes para ajudar a pensar a problemática da ZOPACAS entre aqueles três países ao longo do tempo, como a defesa da Amazônia, o aproveitamento sustentável de seus recursos naturais (minerais e biológicos) e a preocupação mundial com o uso crescente dos oceanos por diversos atores internacionais. Outro contexto geopolítico importante foi a região antártica e subantártica, o que resultou no aumento do interesse desses três países sulamericanos, por causa de sua atividade histórica neste local, além da presença de outros países do Hemisfério Norte e Sul. Isto significa que a importância da Antártica também pode ser um fator de incrementar a cooperação entre os que instalam bases científicas em seu território, no âmbito dos Estados membros da ZOPACAS, e dela para os demais interessados.

A mineração e o aproveitamento das jazidas de nódulos polimetálicos e hidrocarbonetos no solo dos mares desses países também se tornaram algo importante para manter uma expectativa positiva na revalorização da ZOPACAS. Por exemplo, Brasil e Argentina desenvolveram trabalhos de prospecção e exploração de petróleo na área e isso tem se tornado cada vez mais crescente, como é o caso da Bacia de Campos, de Santos e a camada do Pré-sal, que ajudou no 
crescimento econômico do país. Houve também acordos internacionais entre como o que é feito pela Petrobrás e a Yacimentos Petroliferos Fiscales (YPF), da Argentina para prospectar e explorar gás e petróleo no oceano. Isto ocorreu com a finalidade patente de diminuir a dependência do comércio com os países exportadores de petróleo, como no caso dos que são pertencentes ao Oriente Médio.

Esta nova realidade de próspera economia fez com que o Brasil apresentasse o pleito sua preocupação com a defesa do seu mar jurisdicional e pleiteasse sua expansão, advogando diante da ONU o direito de estender suas atividades no Atlântico, com base no estabelecido na Convenção das Nações Unidas para o Direito dos Mares (CNUDM), realizada na Jamaica em 1984. Assim, o Brasil apresentou pedido para que houvesse a aceitação de seus direitos aumentados na área, através do Levantamento da Placa Continental (LEPLAC), feito pela Diretoria de Hidrografia da Marinha. Sendo plenamente aceita esta demanda, aumentaria a faixa de atuação, autoridade e soberania brasileira de maneira significativa, perfazendo uma área um pouco maior que o território amazônico nacional.

Pela importância dos recursos marítimos, a MB denominou de Amazônia Azul a porção do oceano sob jurisdição brasileira, a fim de desenvolver seus interesses no plano internacional. Tal expressão metafórica foi incorporada nos textos oficiais brasileiros, como a Política Nacional de (PND), a Estratégia Nacional de Defesa (END) e o Livro Branco Nacional de Defesa (LBDN), respectivamente de 2005, 2008 e 2013. Além disso, esta atitude contou com o aumento da importância político-econômica do mar pela $\mathrm{MB}$. Isto sendo feito num país que possui quase $7.500 \mathrm{~km}$ de litoral e tem boa parte da sua população vivendo na costa marítima, sendo uma das justificativas para criar o Plano de Articulação e Equipamento da Marinha do Brasil (PAEMB), com destaque para a construção do submarino de propulsão nuclear.

As atividades brasileiras no mar têm também ajudado aos seus vizinhos na prospecção perolífera argentina e de alguns países africanos. Este é um exemplo onde os Estados expressam alguns modos de sedimentar determinadas parcerias capazes de aprofundar a cooperação e dar mais sentido a um mecanismo multilateral que procura ser válido para os seus membros. Houve, então, perspectivas e avanços estabelecidos diante do interesse desses países de aumentar sua capacidade para empreender maior cooperação no interior da Zona de Paz, contribuindo também para o seu desenvolvimento econômico, político e cultural. Contudo, não podemos esquecer a validade dos questionamentos feitos e certos desafios históricos, conforme veremos a seguir. 


\section{Temas e Problemas Existentes}

Entre os países da ZOPACAS houve produtos e serviços militares e empresariais, que auxiliaram no intercâmbio e cooperação dos outros países em questão na América do Sul e na África. Nesta área, criaram-se atividades petrolíferas, de construção civil, salvamento aéreo e marítimo, defesa ambiental, intercâmbio cultural etc., além de ajuda humanitária, integrando muitas ações governamentais entre os seus membros.

Se olharmos para os documentos sobre as políticas de defesa brasileira, argentina e uruguaia vemos que eles tiveram em comum, a manutenção da soberania e a paz entre os países, que podem orientar a maneira de contribuir com a cooperação atlântica. No Brasil, por exemplo, a PDN de 2005, rebatizada de Política Nacional de Defesa, em 2012, tratou de especificar o foco essencialmente voltado para as ameaças externas, procurando distinguir segurança e defesa de maneira mais clara que a versão anterior. A mesma se preocupou em manifestar a necessidade de aprofundar a cooperação e colaborar com o desenvolvimento e a integração entre os países que dele fazem parte do nosso entorno estratégico. Ela pretendeu resolver pacificamente os conflitos e prima pela modernização da infraestrutura dos países sul-americanos de maneira harmonizada e convergente, colaborando para resolver os problemas que venham a causar instabilidade regional. Isto foi prioridade não só para a América do Sul como também para a África, onde o que foi apelidado de Amazônia Azul passou a ter destaque importante (Ministério da Defesa, 2005).

A Argentina adotou o conceito de "defesa estratégica" e abriu mão de declarar hipóteses de conflito com os países vizinhos. Ao contrário, almeja auxiliar a ordem internacional através da cooperação e integração sub-regional e mundial sem buscar a agressividade militar para fins expansionistas, mas, apostou no investimento em missões de paz estabelecidas segundo os princípios e parâmetros das Nações Unidas. A importância da exploração dos recursos do Atlântico Sul, também esteve manifesta ainda no Livro Branco de Defesa Argentina, pois, sua utilização pacífica e sustentada é uma garantia de estabilidade importante para os países costeiros, para quem a tecnologia disponível em diversos setores, deveria ser aplicada para seu controle e proteção (Ministerio de Defensa, 2014:23).O Uruguai, por sua vez, também definiu suas prioridades de maneira semelhante aos seus vizinhos, com a preocupação de mencionar uma "defesa cooperativa”, onde os meios militares são dispostos para a manutenção dos interesses e a soberania uruguaia e a participação do país nos processos de manutenção da paz no âmbito da ONU. Neste sentido, o Estado uruguaio também pretendeu evitar o conflito bélico numa eventual crise com outros países, combinando diplomacia preventiva com dissuasão militar. Em termos regionais, o país buscou a estabilidade e a integração com os parceiros do 
MERCOSUL, como uma das iniciativas que concorram para a melhoria dos interesses comuns e busca de consenso nos fóruns multilaterais internacionais (Ministerio de Defensa, 2005).

Ao longo da sua história, o Uruguai criou sua política externa e seus princípios de defesa após dos acordos realizados com Brasil e Argentina para o reconhecimento de sua independência, no século XIX. Passou, então, a ser considerado como um "estado tampão" por causa da permanência de rivalidades entre brasileiros e argentinos. Entretanto, isto não impediu que o Uruguai tivesse condições de se desenvolver e criar seus próprios interesses, conservar sua soberania e independência no contexto internacional (Storace, 1999:5). Um aspecto importante que perdurou no tempo foi a articulação constante entre a política externa e a política e defesa, quando do estabelecimento dos seus princípios, realizações passadas e atuais, pautados pela soberania, não beligerância, e busca da paz, diálogo e ação diplomática. Isto fez com que, ao longo do século XX o país criasse FFAA dissuasórias, e uma Chancelaria agindo cooperação internacional, multilateralismo, Estado de Direito, justiça, direitos humanos e preservação do meio ambiente etc. Anteriormente, no contexto durante a Guerra Fria, o Uruguai esteve sob a lógica do embate entre as potências mundiais e as superpotências, como as outras nações latino-americanas e viu a eclosão de novas ameaças, além da permanência das tradicionais ao fim da Guerra Fria. Neste período, sua política de defesa buscou manter os objetivos não só da segurança internacional no contexto global, hemisférico continental, regional e sub-regional. Isto de deu na sua participação nas Organizações Internacionais e demais entidades representativas, como a ONU, OEA, MERCOSUL e, posteriormente, na UNASUL. Além disso, este país legitimou a consideração da América Latina, em especial a América do Sul como Zona de Paz (Storace,1999:4).

Mesmo sendo um país pequeno territorialmente, possui uma costa atlântica e nela mantem interesses marítimos relevantes fazendo valer sua autoridade política e econômica no seu uso. Aliado a esta postura, é evidente sua atitude em relação à pesquisa e presença na Antártica, por meio de suas instituições, sobretudo o Instituto Antártico Uruguaio (IAU).

Assim, a defesa nacional uruguaia passou a ser considerado um aspecto mais restrito daquilo que o país entende ser o contexto mais amplo da segurança internacional, a partir da qual se institucionalizaram leis sobre defesa para assegurar o funcionamento desta política pública e as missões gerais e específicas de suas FFAA. Soma-se a isto a estruturação e modernização de seu Ministério da Defesa Nacional a fim de melhor avaliar, planejar e agir frente às possíveis ameaças internacionais. Desta maneira o Uruguai tem investido nas capacidades humanas e materiais de 
seus militares, como ciência e tecnologia, inteligência, informação, treinamento etc, para estabelecer uma ação conjunta das FFAA no que for considerado necessário em cada ocasião. No plano da atuação interna e externa, isto foi feito não só por uma decisão estatal, mas, também com o apoio da cidadania, prática que foi incentivada pelo debate nacional ocorrido entre 2005 e 2006 para pensar nos desafios e problemas no plano político, econômico, social e militar existentes na atualidade (González Guyer, 2013: 124-132).

Os uruguaios criaram marcos de defesa nacional, considerando seus interesses como país na esfera global e regional, para assegurar sua soberania, coesão e mobilização nacional por meio de sua política de defesa e das atividades de assessoria do Conselho de Defesa Nacional (CODENA) composto pelo poder político, com a participação de membros do Executivo, Legislativo e instituições sociais, tal qual institucionalizado pela Lei de Defesa nacional de 2010 (Javier, 2015:71). Nesta lei foi ressaltada a importância dada à ONU e demais organizações internacionais, na busca de um ambiente mundial pacífico, em relação a cada contexto. Para isto esse país age nas suas missões de paz, por intermédio da constituição de um Sistema Nacional de Operações de Paz (SINOMAPA) promovendo operações de paz em vários países, inclusive os africanos.

Apesar de não ser algo necessariamente determinante, ressaltamos que isto se aproxima dos objetivos da criação da ZOPACAS, onde o Uruguai se manteve participante ativo e incentivador do desenvolvimento desta entidade, como na promoção da reunião em Montevidéu de 2013.

Estas operações de paz têm sido relevantes para apoio à política externa deste país e o incremento de recursos financeiros que ajudam a manter os militares treinados e equipados de um modo bastante significativo, o que seria difícil de conseguir de outra forma, sobretudo a partir do início dessa experiência uruguaia em 1991, no Camboja. A cifra chegou a cerca de 1,5\% do PIB nacional e representou quase 5,5\% do orçamento do país (Rial, 2013:145). Na África, os uruguaios têm experiência de missões na República Democrática do Congo, Angola, Moçambique e Costa do Marfim, e auxiliam outros países na América Latina, como Brasil e Argentina também com sua experiência no Haiti, como já dito. Assim, o Uruguai está entre os quinze maiores contribuintes em missões de paz da ONU Consideramos que este aspecto pode ser relevante para pensar as medidas de cooperação que existiram entre esses países e suas FFAA no contexto da ZOPACAS, utilizando a capacidade uruguaia acumulada e sistematizada na Escola de Operações de Paz do Uruguai (ENOPU) da qual se beneficiam Brasil e Argentina e alguns dos Estados africanos. Com efeito, o Brasil resolveu criar um Centro de Brasileiro de Operações de Paz (CIOPAZ-BRASIL) que mantém importantes ligações com esta escola uruguaia. 
Sem deixar de lado as atividades tradicionais de defesa nacional, as operações de paz se tornaram uma marca significativa da Política de Defesa Nacional uruguaia, aprovada em 2014.

$\mathrm{Na}$ realidade brasileira, podemos ressaltar que a decisão brasileira de reforçar a sua capacidade de projeção militar na área também levou à criação de programas de reaparelhamento naval. Estes têm sido um fator de modernização para fazer com que a MB passe a um patamar mais elevado de capacidade dissuasória, contando com o intercâmbio feito com outras Marinhas, como as de países europeus (Silveira, 2011). Tais programas são: PROSUB, Programa de Construção de Submarinos, cujo destaque é a construção de submarinos com propulsão nuclear, além ao Programa do Navio Aeródromo (PRONAE), do Programa de Construção de Navio Anfíbio (PRONAG) e do Programa de Construção de Navios de Superfície (PROSUPER), como novos barcos-patrulha e corvetas da classe Barroso. É necessário dizer ainda que a MB é responsável pela viabilidade do Sistema de Gerenciamento da Amazônia Azul (SISGAaZ), que junta recursos e compartilha informações com outras Forças, para vigiar e proteger o mar brasileiro. Para a defesa aérea a Força Aérea Brasileira (FAB), adquiriu 36 caças Grippen da Suécia e comprou outra categoria de aviões Super Tucano e o cargueiro KC-390 da Embraer. Neste sentido, o país melhorou ainda os equipamentos do Exército Brasileiro (EB), com um novo programa de aquisição de blindados, artilharia antiaérea, helicópteros e a instalação do Sistema de Monitoramento de Fronteiras (SISFRON), com uso de sofisticação tecnológica inédita para a proteção das fronteiras sul e oeste do país, o que também envolveu estrita cooperação de vizinhos como a Argentina, o Uruguai e o Paraguai, dentre outros. Tal procedimento reflete a necessidade da evolução de instrumentos de defesa capazes de permitir vencer as ameaças e tratar de superar as suas vulnerabilidades e possíveis ameaças no Atlântico Sul (Silveira, 2014).

Por sua vez, a Argentina também teve projetos de cooperação militar com os uruguaios, através da indústria de defesa, com o projeto de construção de um veículo aerotransportado intitulado Gaucho. Além do que este país também participa em missões de paz com o Brasil na América Latina e na África Subsaariana e outros lugares do mundo. Como seus parceiros do subcontinente, criou o Centro Argentino de Treinamento Conjunto para Missões de Paz (CAECOPAZ) fazendo intercâmbio com seus vizinhos mercosulinos, por meio das operações militares e intercâmbio de pessoal. Não podemos esquecer que, depois de algumas décadas de tensões e rivalidades com a Argentina, houve maior intercâmbio com o Brasil em áreas sensíveis, como a produção de energia nuclear, o que passou a ter muita significação para ambos, demonstrando terem capacidade de construir medidas de confiança mútua, que se tornaram notórias no plano internacional. Por exemplo, 
eles promoveram várias operações navais e o treinamento de pessoal entre a MB e a Armada da República Argentina (ARA), aviação naval e reparo de submarinos. Este aspecto foi mais ainda importante, no momento em que a MB passou para outro patamar tecnológico com o projeto de construção de submarinos de propulsão nuclear. Outro exemplo de modernização tecnológica foi a declaração feita com o Brasil para aprofundar a defesa cibernética, sobretudo, num momento de vulnerabilidades e medidas de incremento da proteção eletrônica das fronteiras entre seus vizinhos.

Estes mesmos países realizaram ações comuns de proteção do Atlântico Sul na sua margem sul-americana, contando com o apoio de seus sócios da UNASUL e dos africanos, através de suas marinhas, fomentando o diálogo e a integração com exercícios navais, tais como as "Operações Fraterno" iniciadas nos anos 1970 -entre Brasil e Argentina- ou as operações ACRUX e AROV, que incorpora, além desses dois, outros países da região, como Uruguai, Paraguai e Bolívia. Outro exemplo válido foram as operações ATLASUR, que envolve Brasil, Argentina, Uruguai e África do Sul (Flor \& Silva, 2011:58). Jogos de guerra e simulações contribuem ainda para este intuito, tal qual se realiza no interior das escolas de estado-maior destes países. Desta maneira, pôs-se em prática alguns elementos importantes para aumentar o grau de intercâmbio e cooperação, aumentando a consecução de medidas de confiança mútua e a dar conta de iniciativas de segurança cooperativa aos moldes dos objetivos do CDS da UNASUL.

Algo destas iniciativas remonta ao decurso histórico-regional. Nos anos 1950, por causa das questões relacionadas à segurança internacional no período da Guerra Fria, foi instituído o CAMAS (Controle de Área Marítima do Atlântico Sul) para o patrulhamento contra possíveis ameaças soviéticas, onde Brasil, Argentina de Uruguai participaram também com a ajuda da África do Sul, que atualmente, continua em funcionamento para segurança marítima, e estão a cargo desses países sul-americanos. Mas, mesmo unidos pela política mundial, Brasil e Argentina atravessaram um período de rivalidades mútuas até os anos 1970, com os acordos nucleares e a resolução sobre a construção da usina de Itaipu. Esta trajetória de ação multilateral foi incrementada ao longo das últimas décadas e deu às marinhas desses países uma capacidade que pode ser aproveitada pelos outros países da região, colaborando com seus recursos materiais e humanos para o desenvolvimento de uma concertação benéfica e capaz de superar desafios históricos existentes (Silveira, 2010). Tal exemplo de cooperação esteve em consonância com os alvos do CDS da UNASUL ao estimular a troca de experiências e análises de participação em operações conjuntas, missões de paz da ONU etc. Estas trocas contribuíram para a estabilidade regional e sub-regional, segundo o seu Plano de Ação Anual (PAA) que 
visa consolidar alguns eixos importantes para: a) coordenação das políticas de defesa; b) cooperação militar; c) cooperação de indústrias de defesa; e d) formação de recursos humanos respectivos (Machado, 2011:238-239). Para este autor, eles foram considerados bastante válidos para contribuir com o ambiente de paz estabilidade e cooperação entre os países, inclusive os da América do Sul e África.

\section{A ZOPACAS em Debate}

Destacaremos aqui dois tipos de ênfase a favor da ZOPACAS, não necessariamente excludentes, pois se complementam, conforme pode ser visto nos argumentos de alguns autores mencionados abaixo. A primeira possui um arco de abrangência geopolítica interna à área da ZOPACAS, e a segunda tem um arco externo, de maior alcance frente à Zona de influência imediata do entorno estratégico sul-atlântico. Nas duas ênfases, não visualizamos análises marcadamente pessimistas sobre a existência e desenvolvimento dessa entidade, apesar de haver críticas a seu respeito de sua institucionalização.

No primeiro grupo de autores, como Penha (2011), Amorim (2012), Miyamoto (1987), Saraiva (2012) e Yapur (2011), há um enfoque que se poderia chamar de otimismo cauteloso, pois, julgam ter havido ganhos e dificuldades em sua implementação efetiva. Neste caso, leva-se em consideração a presença dos EUA na sub-região e sua postura negativa desde a origem da Zona. Para este conjunto de analistas, o desenvolvimento da ZOPACAS possibilitaria incrementá-la juntamente com outras organizações internacionais do interesse de certo um grupo de países membros situados na sua área de atuação, como é o caso dos países sul-americanos com a UNASUL e, para certas nações, especificamente a Comunidade de Países de Língua Portuguesa (CPLP), constituída em 1994 (CPLP, 2018).

Como já dito, a criação da ZOPACAS em 1986 obedeceu a uma ação política internacional, proposta pelo Brasil, mas houve a negativa dos EUA e a abstenção de outros dezessete países membros da ONU. Este comportamento contribuiu para afastar o risco de necessidade da segurança internacional, que pretendesse a militarização da região através de um tipo de coalizão militar como a Organização do Tratado do Atlântico Norte (OTAN). Entretanto, no período da Guerra Fria, apesar do apoio da Argentina e da África do Sul, foram descartadas as propostas de se criar uma Organização do Tratado do Atlântico Sul (OTAS) para o controle e vigilância da América do Sul e da África. Caso esta fosse criada, aumentaria a influência dos EUA e se apresentaria sem benefício da viabilidade de unir paz e cooperação em várias frentes, desautorizando a importância de um pacto militar naquele momento, mesmo quando Brasil passou a reivindicar, diante da comunidade internacional, nos anos 1970, as suas 200 milhas marítimas, a exemplo 
da Argentina, segundo Penha (2011). Em tempos mais recentes, a discussão sobre a possível interferência dos EUA na região passou pela viabilidade e pretensões do Plano Colômbia, implementado em 2000, que trouxe impactos capazes de sedimentarem propostas reativas à hegemonia desse país, como o CDS da UNASUL. Neste sentido, houve quem entendesse que, com a existência e o investimento na ZOPACAS, poderia ser ainda uma medida que evite o aumento da presença da superpotência e contrabalance esta situação, contribuindo para diminuir sua postura hegemônica na região (Vizentini, 2007:5).

Percebe-se que, de acordo com Penha (2011), a história da ZOPACAS demonstrou as tentativas estatais de torná-la uma realidade efetiva para sul-americanos e africanos. Ao longo das décadas de 1980 e 1990 houve várias reuniões, cuja tarefa era delimitar o campo e dar um tipo de identidade a este mecanismo internacional depois de um período de perda de importância estratégica do Atlântico Sul, com o fim da Guerra Fria. Os sucessivos encontros ocorridos no Rio de Janeiro, em 1988, Brasília em 1994, Cidade do Cabo em 1996, Buenos Aires em 1998 e em Luanda em 2007, foram realizados para dar um perfil voltado à cooperação econômica, desnuclearização, defesa do meio ambiente, desenvolvimento científico e tecnológico, e promoção cultural, bem como o aprimoramento de iniciativas diplomáticas e manutenção da paz entre seus membros, contra conflitos internos e externos e as ameaças do crime organizado transnacional. Nem por isso, os aspectos estritamente militares deixaram de ter importância, por causa da presença de países de outras regiões no Atlântico Sul e seus acordos de cooperação com estados africanos, como o Comando Militar dos EUA na África (AFRICOM) e a reativação da IV Frota da Marinha dos EUA, que atua abaixo do Trópico de Câncer. Houve, também, instalações das bases do Reino Unido nas ilhas sul-atlânticas ao longo de vários anos, embora não haja ameaças belicosas concretas desses e outros estados que venham perturbar a paz sul-atlântica (Penha, 2011:193).

A importância estratégica da ZOPACAS foi também ressaltada por Sérgio Amorim (2012:11), ao considerar as convergências possíveis de serem feitos entre este mecanismo e a criação de um sistema de inteligência sul-americana feita a partir do CDS da UNASUL que beneficiassem os países africanos daquela entidade. Em sua análise, o autor lembra a evolução das reuniões para efetivar a ZOPACAS desde o Rio de Janeiro em 1988 até Luanda em 2007, realizadas para aumentar tais convergências e determinar os rumos das ações, então, a serem implementadas. Com o aumento das chamadas novas ameaças que atingem os africanos e sulamericanos (tais como a pirataria, narcotráfico, migração ilegal, tráfico de pessoas e desastres naturais) houve a oportunidade de pensar o significado do período de estagnação da ZOPACAS e vislumbrar alguma forma de superação de sua 
inoperância. Ainda mais, isto se tornou mais necessário quando passou a existir outros arranjos internacionais, como a União Africana (UA), a Comunidade Econômica dos Estados da África Ocidental (CEDEAO) a (CPLP) e a UNASUL e o MERCOSUL. Para aquele autor, haveria que se problematizar sobre a relevância da ZOPACAS num quadro crescente de internacionalização da África, a partir dos interesses da China e dos EUA no mercado global. Soma-se a isso a ampliação dos interesses brasileiros e argentinos, quanto ao aumento de sua Zona Econômica Exclusiva (ZEE) legitimado a partir de sua contínua atividade petrolífera no Atlântico. Segundo o autor estes são fatos por si só exemplificadores da relevância da região no mercado global e o aumento do interesse das empresas transnacionais. Contudo, as iniciativas brasileiras voltadas para o continente africano não tiveram tanta importância no governo de Fernando Henrique Cardoso, mas, passaram a ter outro valor no governo Lula através da CPLP e dos incentivos à revitalização da ZOPACAS. Neste sentido, aquele autor vislumbrou um aumento do espaço da participação sul-americana em cooperar com os países africanos, tal como haviam sido apontadas por Saraiva, de acordo com Amorim. Esta percepção foi apresentada pelo analista em nome do crescimento da importância geopolítica do Atlântico Sul como um "ponto de inflexão", também fazendo referências à visão de Costa (Amorim, 2012: 17) por causa de seu crescimento econômico. Por outro lado, na ZOPACAS ainda haveria certo grau de fragilidade no plano da segurança e defesa, em função da falta de capacidade das FFAA possibilitarem uma efetiva postura dissuasória contra quaisquer ameaças bélicas externas.

O interesse brasileiro em cooperar com os países africanos foi saudado como algo positivo igualmente por Saraiva (2012), quando o primeiro governo de Dilma Rousseff ajudou a promover a Cúpula América do Sul-África (ASA), com os objetivos de manter a paz e a cooperação pelo desenvolvimento econômico e social da região. Tal iniciativa foi vista por este autor como uma "obrigação estratégica" para o Brasil. Daí, a ZOPACAS representaria igualmente este esforço, por ser um arranjo multilateral que funcionaria como uma "OTAN do Sul", de modo fraco e discreto, mas válido para manter a "pax atlântica". Aliado a esta postura, esteve o incremento da internacionalização da África, como um fator decisivo para aumentar o intercâmbio com este continente, como já feito para Europa, China e EUA. De acordo com Saraiva, os sul-americanos ganhariam muito com iniciativas desta natureza, de acordo com Saraiva.

Mesmo assim, haveria alguns condicionantes sobre a existência real da ZOPACAS desde que foi analisada por Miyamoto (1987:23). Para este autor, deve-se levar em conta o comportamento das grandes potências e manter uma gama de itens no plano interno e externo aos seus países membros. por exemplo, obedecer a 
convenções internacionais criadas pelas grandes potências e respeito à soberania, fim de projetos de militarização, resolução de questões sobre as Malvinas e primar pela supremacia civil sobre o militar.

Outra visão razoavelmente otimista sobre a ZOPACAS está na análise de Yapur (2011:3). A autora argentina apontou que o Atlântico Sul é um denominador comum entre seus membros, tornando-se um valor importante para o incentivo de fazer com que cooperação Sul-Sul, apesar das diferenças físicas e sociais entre os países. De todo modo, neles reside cerca de $1 / 4$ da população mundial, com crescente atividade econômica por causa do petróleo e da formação de blocos regionais. $\mathrm{Na}$ mesma direção de alguns analistas Yapur apresentava as mudanças no mundo pósGuerra Fria que implicaram em perceber com mais clareza e flexibilidade os problemas de segurança internacional com a eclosão das novas ameaças. Tal mudança concorreria para que houvesse a necessidade de pensar de maneira "multidimensional". Conquanto a ZOPACAS tenha tido algumas dificuldades em termos de sua delimitação geográfica do Atlântico Sul, desde seu início seus estados membros almejaram realizar objetivos comuns na construção da paz, no evitar a proliferação nuclear conforme os textos de Tlatelolco e Pelindaba, além da eliminação de conflitos na Zona. A isto, agregou-se a cooperação e o desenvolvimento econômico e social, a ajuda humanitária, a proteção ao meio ambiente, a resolução pacífica de controvérsias e o respeito às normas do direito internacional. Porém, a história recente demonstra que houve conflitos e desavenças, como foi o caso das Malvinas, o regime de apartheid na África do Sul, a luta pela independência da Namíbia e o conflito na Republica Democrática do Congo, além de um grande leque de problemas humanitários e crises políticas nos países africanos. Os aspectos estratégicos não poderiam ser descartados como a necessidade de agir para manter a Zona desnuclearizada, e aumentar os exercícios militares (sobretudo as operações marítimas) como a ATLASUR, para desenvolver o intercâmbio entre Brasil, Argentina e Uruguai. Ademais, para Yapur o processo de tentativas de consolidar a ZOPACAS, por meio de diversas reuniões interministeriais, representariam ganhos e temores que devem ser superados para dinamizar a cooperação em nível econômico, político e cultural. Isso levaria a ter ações concretas para fazer melhorar, de fato, a situação regional e aumente a prosperidade dos países envolvidos.

No segundo grupo de analistas, como Abdenur e Souza Neto (2014 a) e Abdenur e Souza Neto (2014b) há uma ênfase que poderíamos classificar de otimismo oportunista, por causa do contexto das chances de crescimento econômico e da importância do Atlântico Sul para o Brasil e seus vizinhos nas últimas décadas. Houve perspectivas de crescimento das atividades petrolíferas, assim, o intuito de 
consolidação da Zona poderia ser construído junto com o investimento nas iniciativas de maior monta. Este é o caso dos BRICS, Fórum América do Sul-países Asiáticos, Fórum IBAS e Fórum América do Sul-África, ainda que uma parte desses países estivesse fora da ZOPACAS. Há também esforços de cooperação com países europeus membros da União Europeia (UE) segundo já ressaltado, o que contribui para a melhoria da ZOPACAS, enquanto um empreendimento da comunidade internacional.

Neste sentido, Abdenur e Souza Neto (2014a, 6-7) abordaram aspectos mencionados acima, destacando que há uma complexidade na atual dinâmica do Atlântico Sul que implicou na construção de um "cinturão de boa vontade" no seu entorno estratégico buscando viabilizar a identidade regional em palavras e atos. Tal postura representa, no caso do Brasil, a visão de atores estatais e não estatais, que podem ser congruentes e concorrentes na busca pelo protagonismo de nosso país, dentro e fora da região. Por isso, esses analistas evocam teorias construtivistas a fim de fundamentar sua ênfase em demostrar que há uma invenção de regiões políticoestratégicas e áreas de atuação internacional, que faria do Estado brasileiro um país responsável por construir maior clima cooperativo na região por meio de iniciativas voltadas para o Atlântico Sul, dentre as quais, a ZOPACAS. Daí em diante, instituições como a Comunidade de Países de Língua Portuguesa (CPLP) seriam também revalorizadas para ajuda humanitária e haveria mais justificativa para o reequipamento naval e intercâmbio entre os militares da região, sem que isso signifique construir ou participar de uma coalizão aos moldes da OTAN. É notável este aspecto, pois, ao mesmo tempo em que o Brasil legitimou o aumento de sua influência e é questionado por outros países, ele modera sua presença quando participa como observador das operações de combate à pirataria e utiliza parte da capacidade de países da Aliança Atlântica para melhorar sua condição dissuasória. Por exemplo, para aqueles autores, nosso país promoveu acordos militares com EUA e Reino Unido e apresenta ações como a Iniciativa Atlântica, ao lado de Espanha, Portugal e os outros países membros da CPLP. Segundo eles, a Argentina também se tornou mais próxima do Brasil na tecnologia de prospecção petrolífera e na área de energia nuclear, depois de períodos de tensão no passado. Mesmo assim, Buenos Aires veria com bastante atenção o crescimento militar do Brasil e os acordos de cooperação militar com outrem, inclusive o Reino Unido, por causa de suas desavenças históricas com Londres. $\mathrm{Na}$ disputa sobre as Malvinas, este assunto causa polêmicas no subcontinente sul-americano.

A propósito deste tópico, segundo aqueles autores, notou-se que na reunião da ZOPACAS da capital uruguaia em 2013, houve comentários sobre as pretensões 
britânicas em aumentar a militarização no arquipélago das Malvinas, segundo o que foi confirmado pelo gabinete londrino a fim de aprofundar seus interesses na região. Em outra publicação, os mesmos autores analisam a importância do Atlântico Sul para o Brasil e os documentos da defesa nacional que balizam a sua estratégia dissuasória para conter quaisquer crises que abalem a posição do país na região e seus interesses de cooperação com outros países (Abdenur \& Souza Neto, 2014 b: 6). Eles ressaltaram que os seus parceiros têm crescido a partir do incremento do Fórum IBAS, da emersão do BRICS, da atitude voltada à Cúpula América do SulÁfrica como exemplo de mais intensa articulação com países africanos. Além disso, houve a valorização dos recursos petrolíferos recentes do Pré-sal e seu destino para o desenvolvimento do país. Neste caso, tais analistas discutem se, como expresso na reunião de Montevidéu em 2013, uma boa saída, na percepção do governo brasileiro, seria aumentar a importância da ZOPACAS, além de outras tantas iniciativas multilaterais. Esta atitude aprofundava as relações com os países da região, a fim de construir uma identidade comum e evitar o vácuo de poder e a intromissão de qualquer ator estatal que venha provocar instabilidade no Atlântico Sul.

\section{Considerações Finais}

Consideramos que, em relação à ZOPACAS, existem significativas distinções entre os países sul-americanos e africanos que dela fazem parte, mas que apesar das dificuldades resultam nas tentativas de estabelecer um curso favorável a todos seus membros. Depois de uma fase de amortecimento institucional, tentou-se turbinar a ZOPACAS em função das novas ameaças na segurança interacional e no incremento da cooperação Sul-Sul. Por isso os governos desses países procuraram criar uma agenda positiva de diálogo e cooperação que se estende por vários campos das suas relações, inclusive aquelas no setor da defesa. Isto foi feito em treinamento militar, ações humanitárias de desastres naturais ou não, operações de paz, exercícios e operações, ajuda técnica, indústria de defesa etc., como no caso do Brasil em relação aos países africanos. Porém, percebemos que, se algo de mais concreto já seria é possível esperar, em termos de cooperação e integração em defesa na ZOPACAS, devem ser juntos aos membros do MERCOSUL e UNASUL. Mesmo caminhando devagar, algo de significativo começava a florescer, sobretudo na relação com Brasil e seus pares da CPLP, além dos países mais austrais como a Namíbia e a África do Sul. Com esta última, também a Argentina mantem relações históricas tendo, ao lado do Brasil, iniciativas bilaterais importantes. Isto demonstrou a disposição político-diplomática para estruturar os laços e fazer algo que se torne efetivo neste setor. Desta composição participou, igualmente, o 
Uruguai nas atividades da chancelaria e dos militares com sua experiência em operações de paz e monitoramento marítimo.

Para o Brasil este aspecto foi particularmente importante por meio dos esforços de cooperação em tipos de geometria variável, como os BRICS e o IBAS, que se constituem blocos regionais que aumentam a necessidade em cooperar multilateralmente. Tal medida foi favorável ainda para diminuir o impacto da presença dos EUA na região, pois, este país que se manteve oposto à criação da Zona, pois, mesmo tendo considerado o Atlântico Sul estrategicamente marginal, com o apoio do Reino Unido, ele conservou sua presença militar e política na área, a fim de manter seus interesses econômicos e culturais.

Em que pese aspectos problemáticos, os países da ZOPACAS podem interagir, aproveitando oportunidades para modernizar suas FFAA e aumentar a sua capacidade dissuasória. Por isso, diante, desses argumentos expostos, consideramos que as questões expostas neste trabalho são importantes para Primeiro: ajudar a melhor analisar a percepção das chancelarias e dos ministérios da defesa do Brasil, Argentina e Uruguai sobre a criação e o desenvolvimento da ZOPACAS. Segundo, contribuir para pensar sobre os problemas e desafios existentes sobre a ZOPACAS, através de parte da produção literária acadêmica desses países mercoslinos da UNASUL, no âmbito da esfera civil e militar. Terceiro problematizar a situação da ZOPACAS diante da opinião pública em geral, através dos meios de comunicação brasileiros, argentinos e uruguaios, a fim de perceber como a sociedade detecta e atribui importância a este mecanismo de alcance sul-atlântico. Quarto, compreender alguns dos aspectos relevantes de avaliação do estatuto da ZOPACAS através da cooperação multilateral entre os países da UNASUL, através do seu Conselho de Defesa Sul-Americano. Em especial, seria importante para avaliar o impacto no intercâmbio feito na formação de recursos humanos, segundo o que venha ser possível contribuir com os interesses comuns de Brasil, Argentina e Uruguai.

Enfim, apesar da crise recente na América do Sul, nossa apreciação é a seguinte: ainda que se possa questionar seu dimensionamento político, econômico e cultural, a ZOPACAS tem grande importância para o Brasil, Argentina e Uruguai a fim de colaborar para institucionalizar os esforços diplomáticos e estratégicos com o intuito de: a) contribuir para a manutenção da paz entre os estados sul-americanos e africanos diante de potências externas à região; b) a existência e a viabilidade do aumento das medidas de confiança mútua voltadas para intensificar os mecanismos de cooperação militar, sobretudo no caso das marinhas e forças aéreas, na defesa do Atlântico Sul, o que não descarta a importância dos exércitos, a fim de criar bases comuns de uma cultura de defesa nesta área; c) o fomento à montagem de certa 
identidade comum voltada para ampliar nos bens culturais, econômicos e políticos, além da ajuda humanitária, na formação da opinião pública desses países.

\section{Referências Bibliográficas}

ABDENUR, A., E. \& SOUZA NETO, D., M., Atlântico Sul e a Cooperação em Defesa entre o Brasil e a África, em NASSER, R. M \& MORAES , R, F de (editores) (2014) O Brasil e a Segurança no Seu Entorno Estratégico: América do Sul e Atlântico Sul, IPEA, Brasília,292 páginas.

(2014) O Brasil e a cooperação em defesa: a construção de uma identidade regional no Atlântico Sul, em Revista Brasileira de Politica Internacional. No 57 (1): 2014.

AMORIM, S. G. de, (2013) Perspectivas Brasileiras na Convergência entre o SISBIN e a ZOPACAS, em Austral: Revista Brasileira de Estratégia e Relações Internacionais, v.2, n.4, Jul-Dez 2013.

FONSECA JR, G. Mundos Diversos, Argumentos Afins: Notas sobre Aspectos Doutrinários da Política Externa Independente e do Pragmatismo Responsável, em ALBUQUERQUE, J.A. G. de, SEITENFUS, R., CASTRO, S. H. N de. (orgs), (2006), Sessenta Anos de Politica Externa Brasileira (1930-1990): Crescimento, Modernização e Política Externa, vol. 1, 2a Edição, Editora Lumen Juris, Rio de Janeiro,641 páginas.

CARMO, C. do. A América do Sul a China e as Contradições da Política Econômica Externa do Brasil, em CARMO, C. do et all (editores) (2013) Relações Internacionais: Olhares Cruzados, FUNAG, Brasília, 623 páginas.

COMUNIDADE DOS PAÍSES DE LÍNGUA PORTUGUESA-CPLP (2018), www.cplp.org. Acesso em 11.12.18.

COSTA, W.M. da, (1991) Geografia Politica e Geopolitica: Discurso sobre o Território e o Poder, EDUSP, São Paulo, 352 páginas.

FLOR, C.R \& SILVA, A,. H., L. da, (2011) UNASUL, Conselho de Defesa SulAmericano e Cooperação: Lições de Cooperação Militar entre as Marinhas de Brasil, Argentina e Uruguai, em Revista da Escola de Guerra Naval, Rio de janeiro, v 17, n 2, jul-dez 2011.

GONZÁLEZ GUYER, J. (2013),em PION BERLIN, D. , UGARTE, J. M (editores), Organización de la Defensa Y Control Civil de las Fuerzas Armadas em América Latina, Jorge Baudino Ediciones, Buenos Aires, 310 páginas. 
JAVIER, J. M.(2015) La Política De Defensa Nacional En Uruguay, em Revista de Derecho Público - año 24 - número 47 - julio 2015 - pp. 69-86 69

LECHINI, G., a Cooperação Sul-Sul Ainda é Possível? O Caso das Estratégias do Brasil e dos Impulsos da Argentina em Direção à Nova África do Sul à África, em : VILLA, R.D. / MATHIAS, S.K.(editores) (2004) Ensaios Latino-Americanos de Politica Internacional, Hucitec, São Paulo, 269 páginas.

MACHADO, A., da S.(2011), A Lógica da Segurança no Projeto de América do Sul: componentes do regionalismo brasileiro, em Revista da Escola de Guerra Naval, Rio de janeiro, v 17, n 2, jul-dez 2011.

MATTOS, C. de M. (1958). Projeção Mundial do Brasil. Geopolitica, Biblioteca do Exército Editora e Editora da FGV, Rio de Janeiro.

MINISTÉRIO DA DEFESA, (2014) Política Nacional de Defesa / Estratégia Nacional de Defesa, MD, Brasília.

A Zona de Paz e Cooperação do Atlântico Sul, ZOPACAS,https://www.defesa.gov.br/relacoes-internacionais/forunsinternacionais/zopacas, Acesso em 07.08.2013.

MINISTERIO DE DEFENSA ARGENTINO, (2014) Informe: Politica Nacional de Defensa, www.mindef.gov.ar. Acesso em 15.10. 2014.

MINISTERIO DE DEFENSA, (2005) Uruguay. La Defensa Nacional. Aportes para un Debate, Montevideo, Ministerio de Defensa.

MINISTERIO DAS RELAÇOES EXTERIORES, (2016) Documentos da União das Nações Sul-Americanas (UNASUL) http://www.itamaraty.gov.br/pt-BR/politicaexterna/integracao-regional/13221-documentos-da-uniao-de-nacoes-sulamericanas. Acesso em 28.12.19.

MIYAMOTO, S., (1987) Atlântico Sul: zona de paz e de cooperação?, Lua Nova Vol.3, No.3,1987.

PENHA, E. , A., (2011) Relações Brasil-África e Geopolitica do Atlântico Sul, EDUFBA, Salvador.

RIAL, J, (2015) La Relevancia de las Misiones de Paz para las FFAA de Uruguay, Montevideo, Revista Naval, Edicion 25 anos de Aniversario, No 74, Agosto 2015. ARAIVA, J. F. S. (2014),As Asas do Sul, uma da Paz e a outra do Desenvolvimento, 
Observatório Grupo de Estudos da África, Instituto de Relações Internacionais da Universidade de Brasília (GEA/IREL-UnB) observatoriodaafrica.wordpress.com. Acesso em 20.10. 2014.

SILVA, G. C. e (1967). Geopolitica do Brasil, José . Olympio, Rio de Janeiro.

SILVA, J. T. da, A Nova Percepção Marítima Chinesa e os Jogos de Poder na Ásiapacífico, em CARMO, C. do, et all (editores),(2013) Relações Internacionais: olhares cruzados, FUNAG, Brasília.

SILVEIRA, C. de C., (2010) A Formação Militar-Naval Brasil-Argentina no Contexto de Cooperação no Atlântico Sul: visões sobre a situação regional. História (São Paulo. Online) v 29, 2010.

Pensamento Naval Brasileiro e o Legado de Armando Vidigal, em MONTEIRO, A., WINAND, E \& GOLDONI, L. R. (editores) (2014) A Defesa da Amazônia, VII ENABED, Editora UFS, 533 páginas.

(2011) Política Internacional e Cultura de Defesa na Marinha do Brasil e na Armada Espanhola. Mural Internacional (Online), v.03,

STORACE, J. L (2015), Bases Para Una Politica De Defensa Nacional, http://www.oas.org/csh/spanish/doclibrdefUrug.asp. Acesso em 05.02. 2020.

TRAVASSOS, M. Projeção continental do Brasil. São Paulo: Editora Nacional, 1947.

VIZENTINI, P. F, (2007) Brazil: The Dialectical Nature of Security and Integration in South America Policy: issues \& actors. Vol 20, No 9 Centre for Policy Studies Johannesburg South Africa, April 2007.

YAPUR, M. V (2011), Cooperación Sur-Sur. El Caso de la "Zona de Paz y Cooperación del Atlántico Sur” (ZPCAS), Doc. de Trabajo, “Comité de Asuntos

Africanos, de los Países Arabes y Oriente Medio. Consejo Argentino para las $R$ e l a c i o $n$ $\begin{array}{llllllllllll} & s & A & r & g & e & n & t & i & n & a & s\end{array}$ http://www1.hcdn.gov.ar/dependendias/ieeri/ennee/vi/Tema\%203/Mar\%C3\%ADa\%20Vi rginia\%20Yapur.doc: Acesso em 11.12.15 